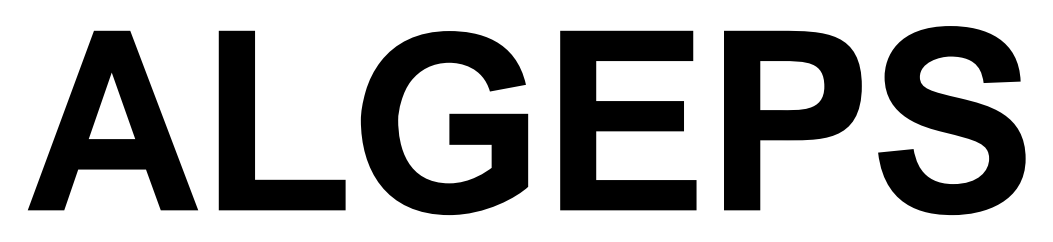

REVISTA DE GEOLOGIA, SĖRIE B no 640 - Juliol del 2013

ITINERARI GEOLÒGIC-MINERALÒGIC PER LES COMARQUES DE LA GARROTXA, LA SELVA I OSONA: DES DE LES PRESES AL FAR, RUPIT, TAVERTET, L'ESQUIROL Y VIC

Josep M. Mata-Perelló i Joaquim Sanz Balagué

Aquest recorregut va ésser experimentat amb docents el dia 15C DE GENER DEL 2012 


\section{ITINERARI GEOLÒGIC-MINERALÒGIC PER LES COMARQUES DE LA GARROTXA, LA SELVA I OSONA: DES DE LES PRESES AL FAR, RUPIT, TAVERTET, L'ESQUIROL Y VIC ${ }^{1}$}

Per Josep M. Mata-Perelló i Joaquim Sanz Balagué

\section{ADVERTIMENTS}

Es tracta d'una sortida efectuada fa uns set anys, la qual ha estat modificada, amb la introducció de noves observacions. Tot i així, gaudeix del mateix fil conductor que va tenir aleshores.

Per d'altra banda, és una clàssica sortida geològica $i$ mineralògica, estructurada en una sèrie de PARADES o ESTACIONS. En cada una d'elles es faran les observacions geològiques i/o mineralògiques pertinents que s'escaiguin.

En qualsevol cas, cal tenir sempre una cura molt especial de respecte a la natura, al llarg de tot el recorregut; de l'itinerari.

\section{BREU INTODUCCIÓ}

La totalitat del recorregut d'aquest itinerari discorrerà exclusivament per una sola de les unitats geològiques que constitueixen el subsòl del nostre país, concretament per la Depressió Geològica de l'Ebre.

Tot i així, s’iniciarà dintre dels sectors corresponents a la Serralada Transversal. Així, al llarg de tot el recorregut s'aniran trobant exclusivament afloraments dels materials cenozoics que reblen l’esmentada depressió.

Malgrat que el recorregut de l'itinerari discorrerà exclusivament per la Depressió Geològica de l'Ebre, al llarg del recorregut, s'efectuaran reconeixements a distància de les altres dues unitats que constitueixen el subsòl de Catalunya: tant dels Pirineus (situats al Nord dels sectors per on discorrerà el recorregut) com dels Catalànids (ubicat al SE).

\footnotetext{
1 AQUESR RECORREGUT ES UNA MODIFICACIÓ I AMPLIACIÓ DEL RECORREGUT: ITINERARI GEOLÒGIC - MINERALÒGIC PER LES COMARQUES DE LA GARROTXA I D“OSONA: DES DE LES FRESES AL FAR, RUPIT, CANTONIGRÓS I VIC / 15 DE GENER DEL 2012 (ALGEBS 638)
} 
Per d'altra banda, el present recorregut transitarà per tres comarques. Així, s’iniciarà a la comarca de la Garrotxa (integrant de les Terres de Girona), per a continuar per la comarca de la Selva (també de les Terres de Girona) i finalitzar dintre de la comarca d'Osona (situada dintre de la denominada Catalunya Central).

\section{OBJECTIUS GENERALS}

A través d'aquest itinerari geològic-mineralògic, s'intentaran d'aconseguir els següents objectius:

1.- Observació de la Zona volcànica de la Garrotxa (inclosa a la Serralada Transversal Catalana), de les seves estructures i dels seus materials. Així, aquesta observació la podrem fer fonamentalment des del Mirador de Xenacs.

2.- Observació de la Serralada Transversal Catalana (part integrant de la Depressió Geològica de l’Ebre) i en concret del sectors corresponents al Cabrerès. Això ho podrem fer des de diversos indrets del recorregut; especialment entre el mirador del Far i Rupit.

3.- Observació dels materials cenozoics que reblen la Depressió Geològica de l'Ebre (i tanmateix la Serralada Transversal Catalana), entre les Preses i el final del recorregut, prop de Vic a l'Esquirol. Aquests materials es distribueixen entre les següents unitats biostratigràfiques: Formació Armàncies, Formació Beuda (amb nivells de guixos blanc i grisosos), Formació Banyoles, Formació Coubet (amb conglomerats, gresos i calcàries), Formació Bracons, Formació Bellmunt, Formació Folgueroles (amb gresos i microconglomerats grisos), Unitat del Puigsacalm Superior (amb conglomerats, gresos i calcolutites grises) i Unitat Vidrà Inferior (amb gresos i calcolutites grises).

4,- Observació, a distància de les estructures de la Zona d'Apilaments Antiformes del Freser (del Sistema Pirinenc), que veurem al Nord del recorregut, des del Mirador de Xenacs, al principi del recorregut. I tanmateix: observació del Canigó.

5.- Observació, a distància dels materials paleozoics (del Cambro-Ordovicià al Permià), que constitueixen la Zona d'Apilaments Antiformes del Freser.

6.- Observació des del Mirador del Far, del contacte, entre l'esmentada Serralada Transversal, i la Serralada Prelitoral Catalana del Sistema Mediterrani. Aquest contacte es fa palès al Sud del Far, mirant a Sant Martí Sacalm.

7.- Des del mateix indret, observació dels relleus de la Serralada Prelitoral Catalana (en el seu sector corresponent a les Guilleries). Aquests relleus es situen al Sud del Far i de Sant Martí Sacalm.

8.- Observació, al llarg del recorregut dels diferents elements del Patrimoni Geològic i Miner, que es vagin trobant. Aquest és cas de la Zona Volcànica d'Olot i dels Cinglés del Far-Tavertet, entre altres indrets. 


\section{ANTECEDENTS}

No tenim cap constància de l'existència de cap itinerari, que discorri íntegrament pels indrets on ho fa el present. Existeixen però, alguns antecedents com els següents: farem esment d'uns itineraris nostres, com: MATA-PERELLÓ (1996, 1999 i 2007). També farem esment dels treballs de DURÁN I GOLD (1990) i GASSIOT i RIERA (1981). També cal considerar el recorregut immediatament precedent, que hem esmentat al peu de pàgina, de la primera pàgina (MATA - PERELLÓ, 2012), que en aquest recorregut ampliant, tot donant una altra alternativa.

Pel que fa a les característiques generals de la geologia regional, farem esment de dos treballs: GUIMERÀ et altri (1992), i RIBA et altri (1976). I, pel que fa a la geologia de la zona per la qual discorre el recorregut de l'itinerari, farem esment dels següents treballs: ARAÑA et altri (1983), IGME (1994a i 1994b), MALLARACH (1968) MALLARACH i RIERA (1981).

També, pel que fa a les mineralitzacions situades a les comarques per les quals discorre 1'itinerari, farem esment d'un treball nostre; concretament de: MATAPERELLÓ (1991).

Tots aquests treballs figuren relacionats, per ordre alfabètic a l'apartat dedicat a la BIBLIOGRAFIA.

\section{RECORREGUT DE L'ITINERARI}

L'itinerari s'iniciarà al poble de les Preses, per tal de pujar fins al mirador de Xenacs, per on es farà una aturada. Després ens caldrà tornar a les Preses, per tal de continuar cap a Bas (tot anant per la carretera comarcal C - 63 (1'antiga C-152). A continuació, 1'itinerari s’adreçarà cap el Coll de Cendreu (seguint ara per la carretera C153), i des d'aquí cap al Mirador del Far, per una carretera local. En arribar-hi es farà una nova aturada.

Tot seguit ens caldrà retornar a la carretera comarcal C - 153, per tal d'arribar cap a Rupit, per on es farà una nova aturada. Tot seguit el recorregut continuarà per la mateixa carretera fins a trobar el camí - carretera cap que es dirigeix cap a Tavertet. En aquest recorregut farem una nova aturada i una altra a la costat del mateix poble. Tot seguit, el continuarà cap a l'Esquirol (Santa Maria del Corcó). Aquí es tornarà a trobar la carretera C-153, per la qual es continuarà cap a la Ciutat de Vic, per on finalitzarà, després de fer-se diverses aturades.

\section{DESCRIPCIÓ DE L'ITINERARI}

Com ja es habitual, aquest itinerari s'estructurarà en una sèrie d'estacions (parades o aturades). En cada una d'aquestes parades es faran descripcions geològiques o mineralògiques, segons s'escaigui. En cada cas s'indicarà el número del mapa topogràfic 
a escala 1:50.000 on es troba l'indret. En aquest cas, el recorregut de l'itinerari passarà per part dels dos següents fulls: 257 (dit d'Olot), 294 (o de Manlleu), 295 (o de Banyoles) i 333 (o de Vic). En tots els casos, aquests fulls són del IGC (Instituto de Geografia y de Cartografia de España). Així doncs, la descripció de les diferents aturades que constitueixen el recorregut de l'itinerari, és la següent:

PARADA 1. MIRADOR DE XENACS INFERIOR, (terme municipal de les Preses, comarca de la Garrotxa). (Full 295).

L'itinerari s'inicia a la sortida de la població de les Preses. A uns 500m, anant cap a Sant Esteve del Bas, es troba un camí (per la dreta de la carretera) que condueix cap al mirador de Xenacs. En un recorregut d'una mica més de $4 \mathrm{Km}$, per una pista en bon estat, s'arriba a l'Àrea de Xenacs. Després, per un sender ben senyalitzat, cal anar a peu fins al Mirador Inferior. Aquí realitzarem la primera aturada, a uns 300 metres de l'aparcament.

Tot aquest recorregut, des de les Preses fins al mirador de Xenacs, es realitza entre els materials terciaris de l'Eocè, constituïts per nivells de gresos, margues i calcàries, els quals cabussen clarament cap a l'Oest. Aquests materials pertanyen als primers trams del recorregut a la Formació Puigsacalm; mentre que els trams més alts corresponen a la Formació Bellmunt, tot i que aquests ocupen una posició estratigràfica inferior en relació als anteriors.

Des d'aquest indret, mirant cap a Olot (al NE) es poden veure clarament els tres volcans més representatius que l'envolten: el Montacopa (tocant a la població), el Garrinada una mica al ENE i Mont Olivet (al seus sectors lleugerament septentrionals). També es pot veure un ampli sector de la Zona Volcànica d'Olot. FOTOGRAFIA 1.

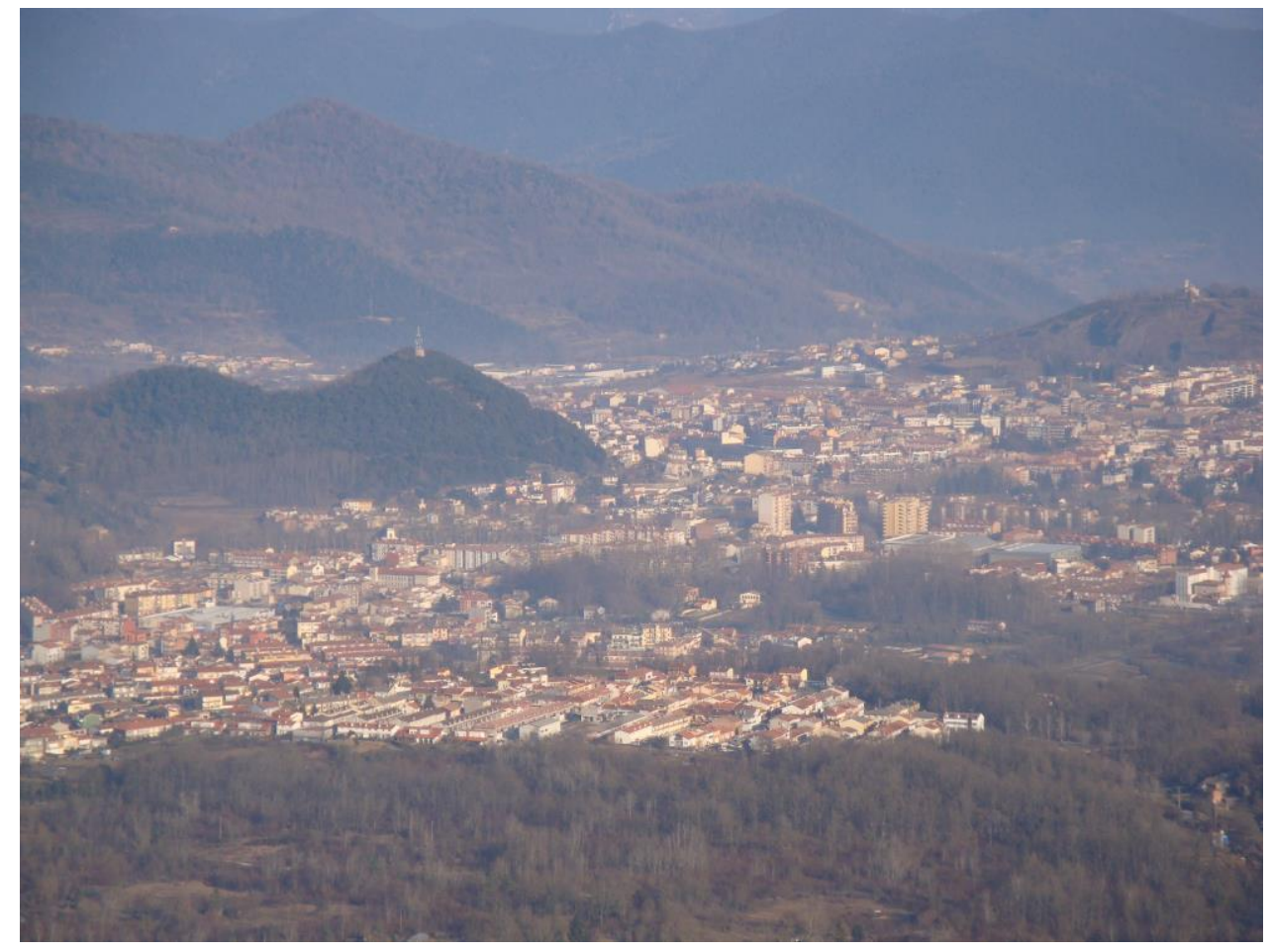


Tanmateix, des d'aquest indret, es fa ben palesa la Serralada Transversal Catalana, amb el Puigsacalm; així com de diversos indrets del Sistema Pirinenc, fent-se palesos molts sectors de la seva Zona Axial, com el Canigó i el Costabona, entre altres indrets. Igualment es fan palesos molts sectors corresponents als Pirineus Meridional, com el Massís del Montgrí. FOTOGRAFIA 2.

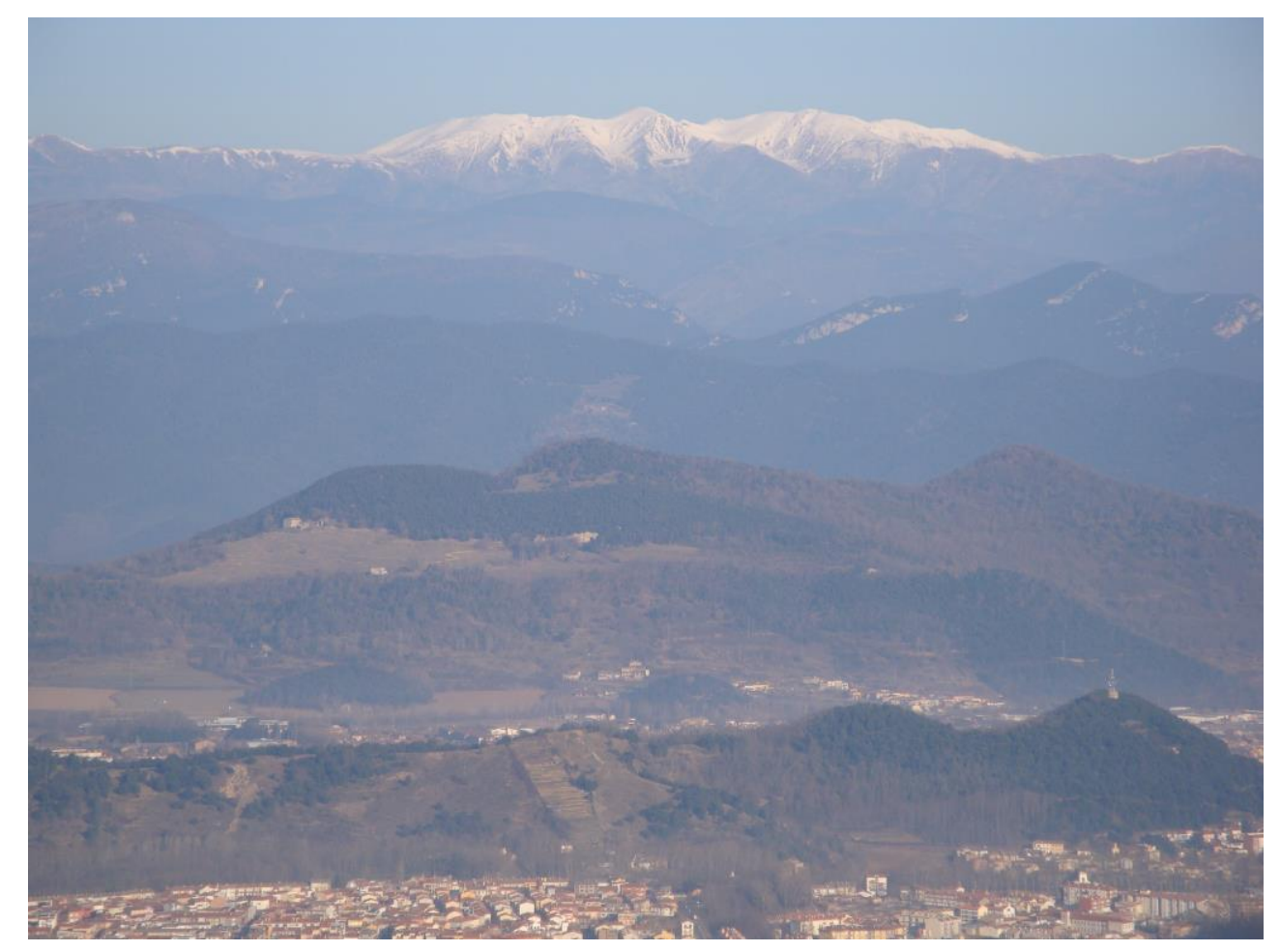

FOTOGRAFIA 2.

En primer terme Olot i el Mot Olivet. Sen segon i tercer la all de Riudaura i la Vall de Bianya. Al fons la Zona Axial amb el Canigó

PARADA 2. MIRADOR DE XENACS SUPERIOR, (terme municipal de les Preses, comarca de la Garrotxa). (Full 295).

Després de realitzar l'aturada anterior, cal retrocedir fins a l'aparcament de Xenacs, per tal de continuar a peu cap al Mirador de Xenacs Superior. Hi arribarem després d’una lleugera pujada d'uns 30 - 35 minuts. Aquí farem una nova aturada.

Com al cas anterior, tot aquest recorregut, es realitza entre els materials terciaris de 1'Eocè, constituïts per nivells de gresos, margues i calcàries, els quals cabussen clarament cap a 1'Oest. Aquests materials pertanyen fonamentalment a la Formació Bellmunt, tot i que aquests ocupen una posició estratigràfica inferior en relació als anteriors, però trobant-nos més enlairats que a l'anterior aturada. 
Des d'aquest indret es pot gaudir d'una visió complementària de l'anterior, en relació amb la Zona Volcànica de la Garrotxa. Així, ara es poden veure els volcans del terme de Santa Pau. Concretament es pot veure el Volcà de Santa Margarida i el Cruscat, entre antres. FOTOGRAFIA 3.

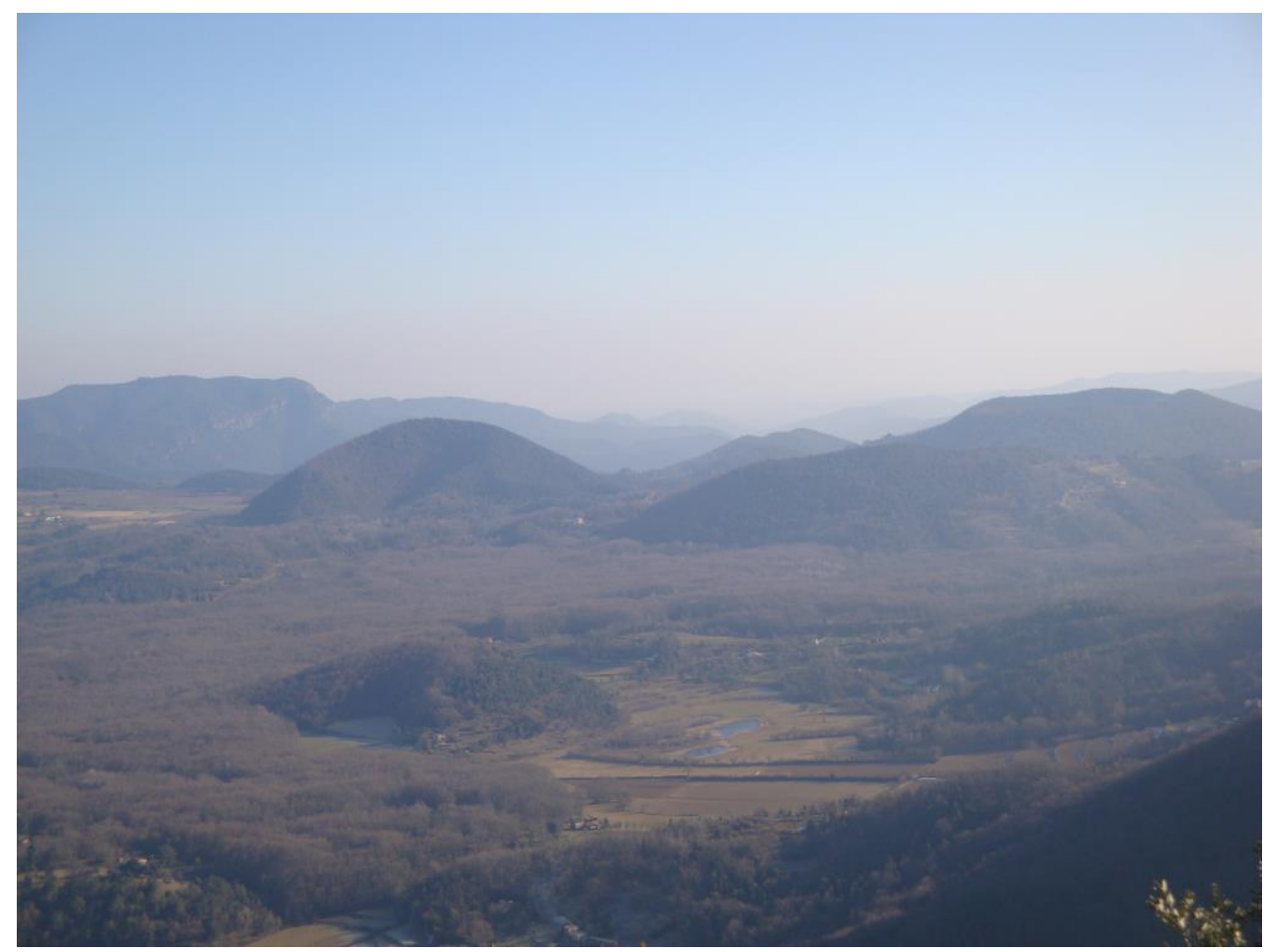

FOTOGRAFIA 3

Zona volcànica de la Garrotxa. Santa Margarida i el Cruscat, des de Xenacs

Per d'altra banda, en aquest recorregut que hem fet des de l'Aparcament de Xenaca fins al Mirador Superior, haurem tingut ocasió de veure alguns aparells kàrstics, desenvolupats entre els nivells carbonatats que hem travessat, així haurem vist el Clot de les Gripies (FOTOGRAFIES 4 i 5), entre altres.

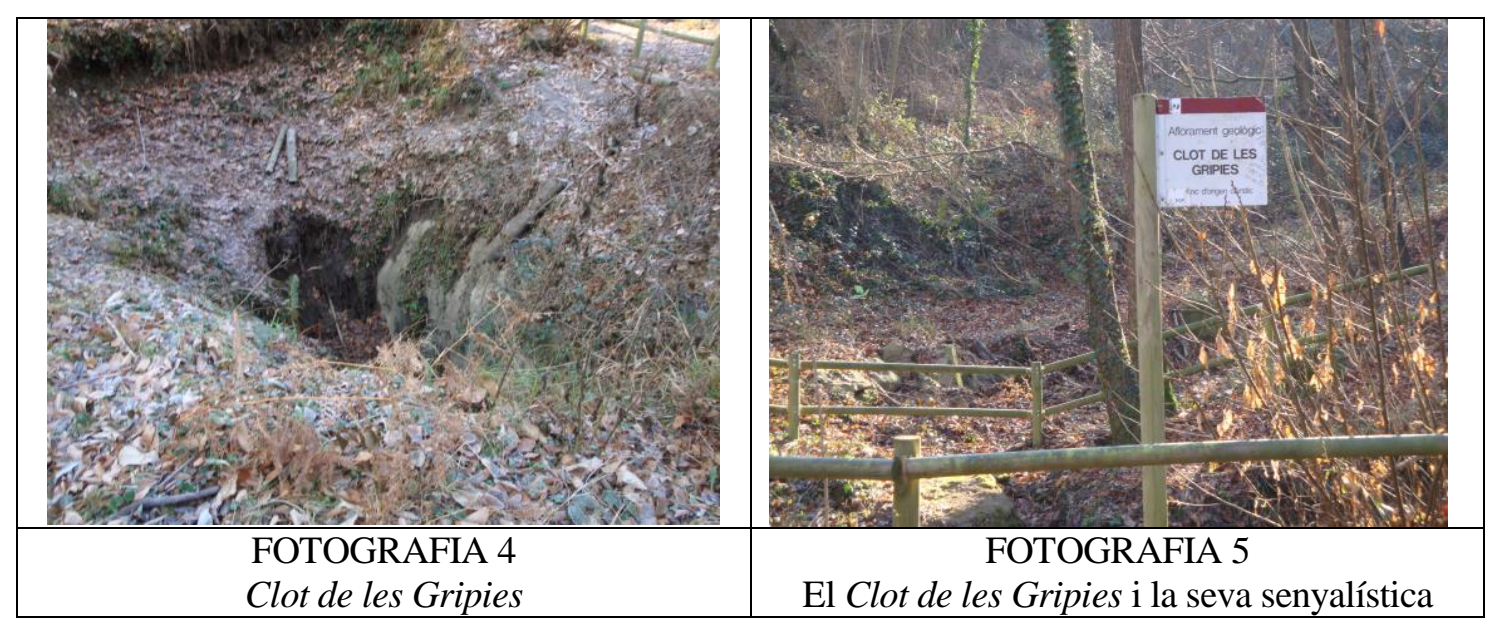

Finalment, cal dir que al costat del Clot de les Gripies, hi ha un exemple molt 
didàctic del procés de formació de carbons vegetals, naturalment artificials.

PARADA 3 - CONDICIONAL. ENTRADA A JOANETES, (Joanetes, terme de la Vall d'En Bas, comarca de la Garrotxa). (Full 294).

Després de realitzar la parada anterior, ens caldrà baixar de nou cap al poble de les Preses . En arribar-hi, ens caldrà seguir per la carretera C- 63 (l'antiga C-152). Per aquesta carretera, en arribar al veïnat de Joanetes (de la Vall d'En Bas), podem fer una nova aturada, després de recórrer uns $10 \mathrm{Km}$ des del Mirador de Xenacs.

Tot aquest recorregut, des de la parada anterior fins a l'indret de l'aturada, es van trobant afloraments dels materials terciaris de l'Eocè, constituïts per nivells de gresos, margues i calcàries, els quals cabussen clarament cap a l'Oest.

Des d'aquest indret, tot mirant cap al NW es pot gaudir de l'interessant relleu del Puigsacalm, situat al Cabreres. Es situa entre afloraments cenozoics, els quals formen un interessants relieves en cuesta.

\section{PARADA 4. COLLET DE LA CARRETERA AL MIRADOR DEL FAR (terme municipal de Susqueda, comarca de la Selva). (Full 295).}

Des de la parada anterior, cal continuar per la carretera C - 63 (l'antiga C - 152), anant sempre cap a ponent. Més endavant trobarem la cruilla d'aquesta carretera amb la C - 153, per la qual ens caldrà continuar el recorregut, arribant al Coll de Cendreu. I, tot seguit, des d'aquest punt s'anirà fins al Santuari del Far, per una carretera local. En arribar a un collet entremig, farem una nova aturada, després de recórrer uns $17 \mathrm{Km}$ més.

El recorregut, des de la parada anterior, es realitza sempre entre els materials terciaris eocènics de la Serralada Transversal Catalana. Així, des del Coll de Cendreu fins al Far es van tallant els nivells de margues grises i els de calcàries nummulítiques, que constitueixen el cingle del Far i que veurem a la parada següent

Tot i així, en aquest indret ens trobem en una posició lleugerament superior a la de les calcàries esmentades, que aflorem per sota nostra, malgrat trobar-nos possiblement més baixos que el Far. Així en aquest indret afloren uns nivells calcolutites grises, que pertanyen a la Formació Puigsacalm. Aquestes calcolitites apareixen formant aixaragallaments, no del tot ben desenvolupats. FOTOGRAFIA 6 (pàgina següent).

\section{PARADA 5. MIRADOR DEL FAR (terme municipal de Susqueda, comarca de la Selva). (Full 295).}

Des de la parada anterior, cal continuar cap al Santuari del Far, per on hi ha el Mirador del Far. En uns $3 \mathrm{Km}$ hi arribarem. En arribar-hi farem una nova aturada al costat del mateix.

Des d'aquest indret es pot gaudir de l'observació de la "calma" triàsica de Sant Martí Sacalm, desenvolupada amb els materials d'aquest període cobrint als paleozoics, dintre de la Serralada Prelitoral Catalana. Més enllà es pot veure amplament 
l’esmentada Serralada Prelitoral Catalana. FOTOGRAFIA 7 Pàgina següent).

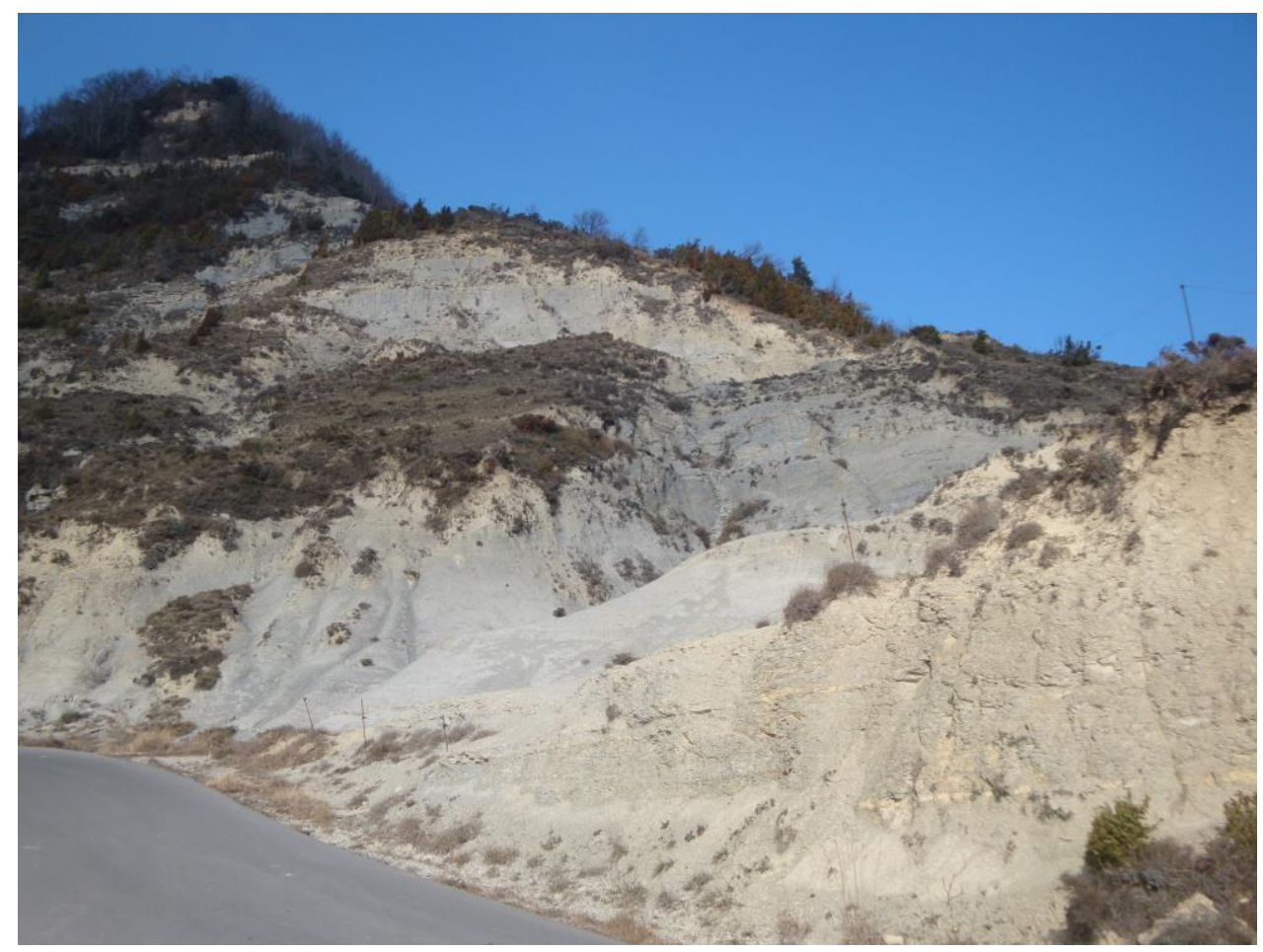

FOTOGRAFIA 6 (PARADA 4, PÀGINA ANTERIOR)

Aflorament de les calcolutites de la Formació Puigsacalm, a la carretera del Far

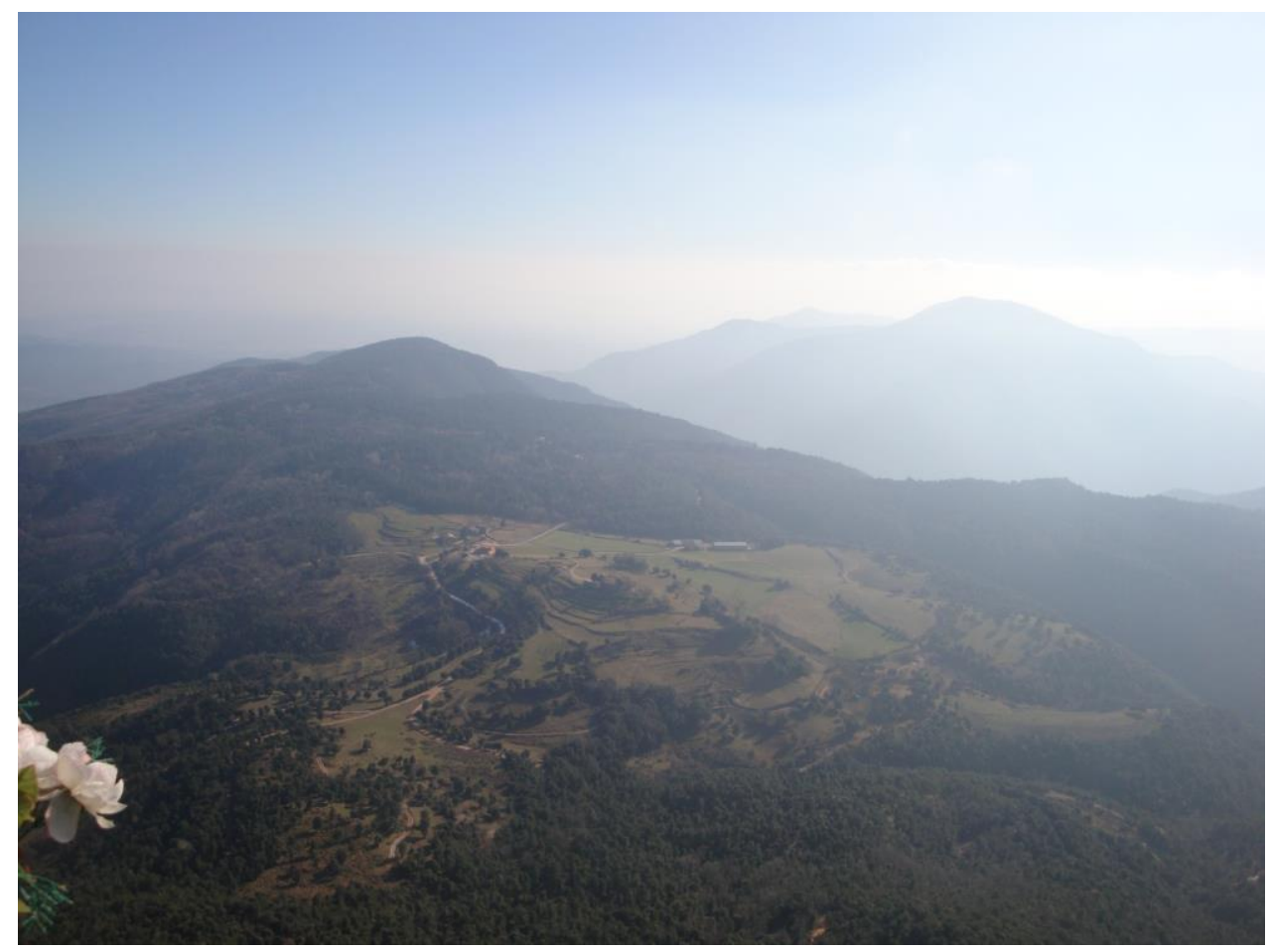

FOTOGRAFIA 7 (PARADA 5, PÀGINA ANTERIOR)

La Calma de Sant Martí Sacalm. Serralada Prelitoral Catalana 
Per d'altra banda, aquí hi ha un lloc per fer una bona observació de la discordança entre els materials terciaris de la Serralada Transversal Catalana (que constitueixen els relleus del Far), i els paleozoics (i triàsics) de la Serralada Prelitoral Catalana, situats per de sota del mirador de Far, a Sant Martí Sacalm. Efectivament, aquí gaudim d'un indret privilegiat, en trobar-nos situats sobre el mateix cingle. FOTOGRAFIA 8.

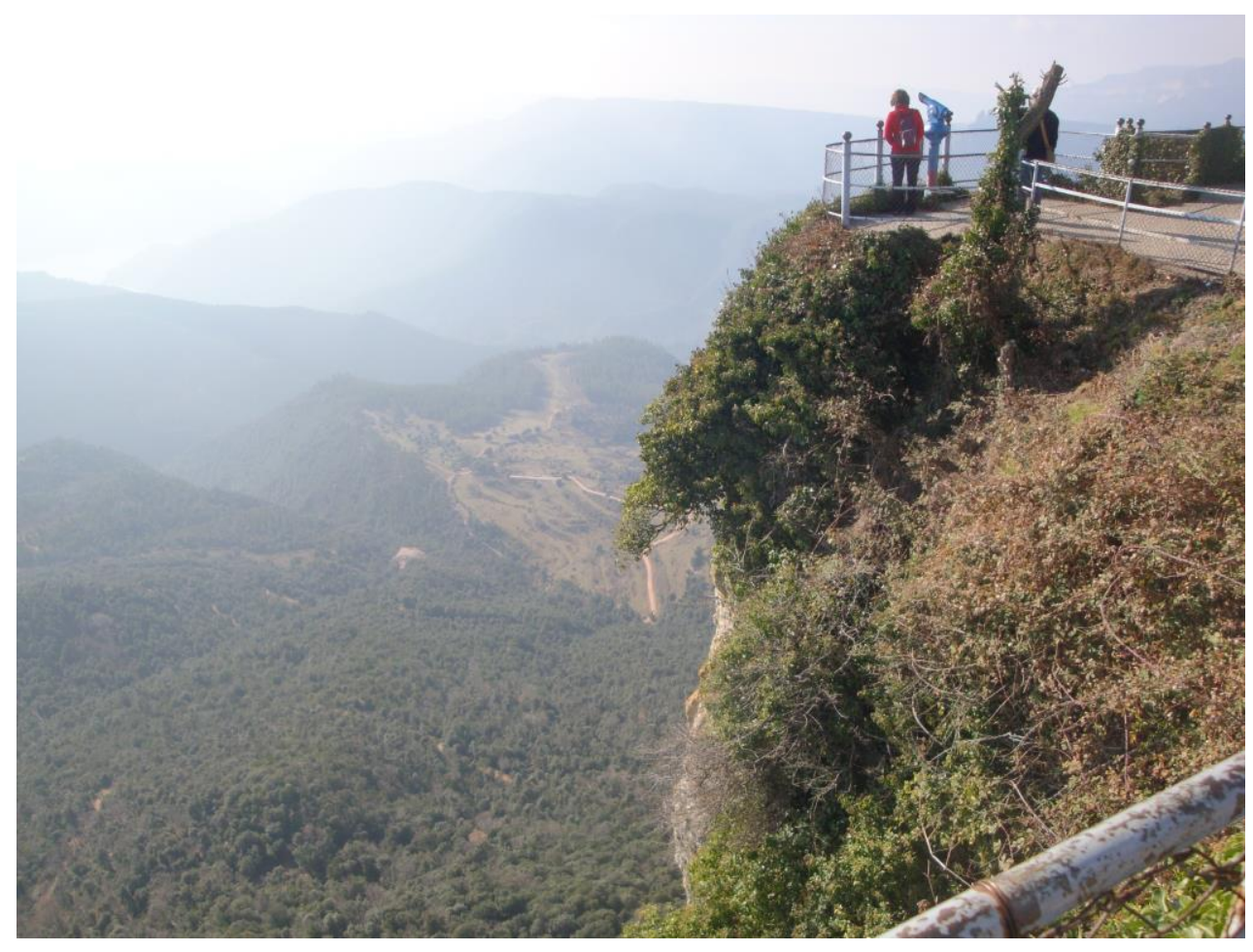

FOTOGRAFIA 8 (PARADA 5)

El Mirador del Far, sobre la plana de Sant Martí Sacalm

Tanmateix, des d'aquí, es pot veure com la Falla d'Amer, trasllada cap al NNE els materials que aquí veiem, situant-los a Sant Climent d'Amer, més baixos i a uns 5 $\mathrm{Km}$ de desplaçament horitzontal; fins i tot es veu com la vall del riu Brugent ha aprofitat aquesta falla. Tanmateix es veu, prop del Pasteral, com el riu Ter agafa aquesta mateixa direcció amb el seu aiguabarreig amb aquest altre riu.

Per d'altra banda, des d'aquí mateix, es poden observar els relleus "en cuesta" dels materials eocènics de la Serralada Transversal Catalana, entre Tavertet, Rupit, Sant Joan de Fàbregues i el Far. Precisament, continuarem ara l'itinerari cap a ponent, anant cap els indrets acabats d'esmentar. Així, des d'aquí es pot veure com actua la Falla de Rupit, aixecant les calcaries cap a ponent. Es tracta d'una falla transversal, similar a la que hem vist mirant cap a la Vall de Brugent, que desplaça els materials en una direcció NNE - SSW.

També es pot veure com sota dels materials anteriors (les calcàries del Far) apareixen uns nivells rogencs, formats per gresos i calcolutites d'aquestes tonalitats que pertanyen a la Formació Vilanova de Sau, que veurem més amplament a les parades següents. FOTOGRAFIA 9. 


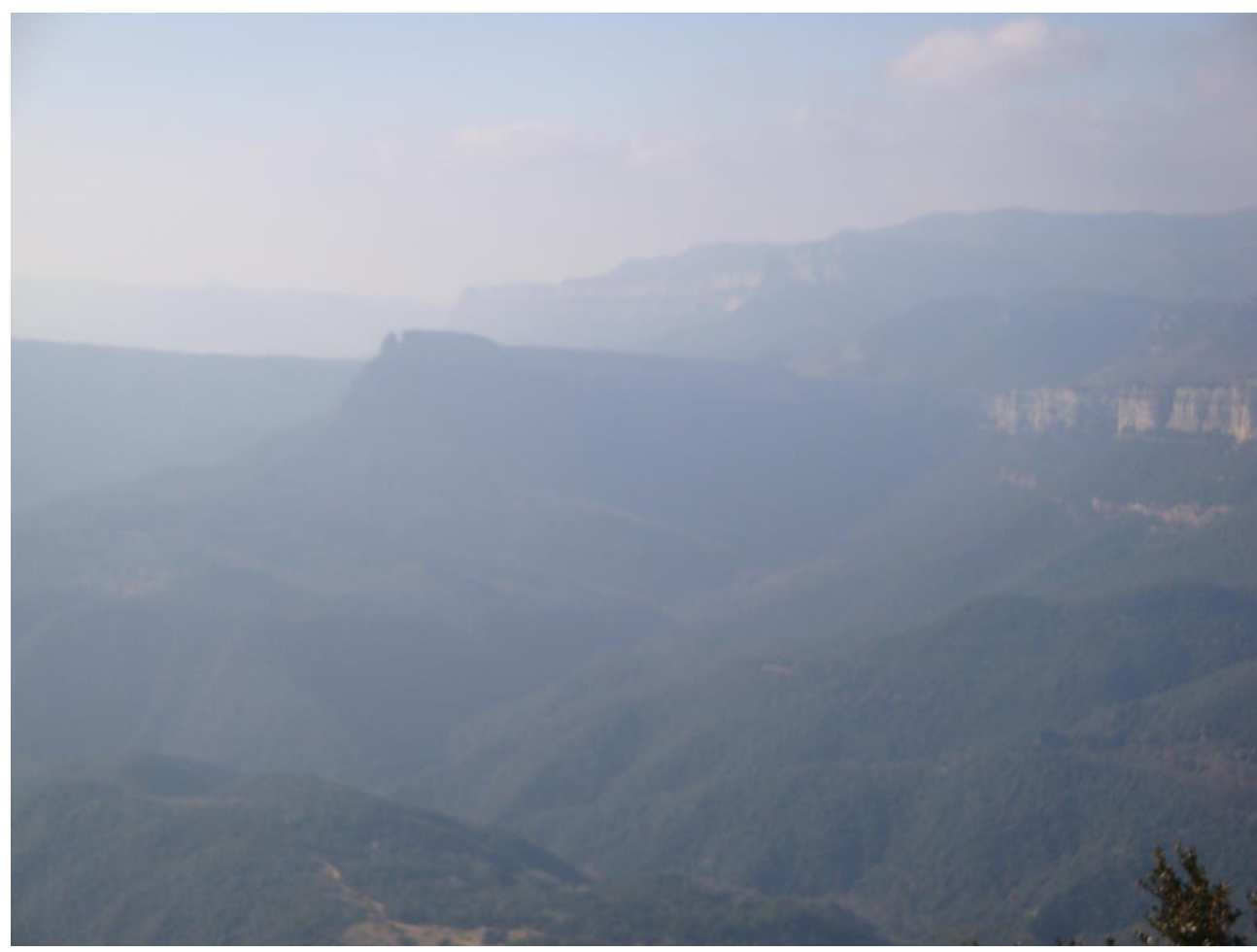

FOTOGRAFÍA 9. (PARADA 5)

Relieves en cuesta dels materials eocènics.

S’endevina la Falla de Rupit, que enlaira les calcàries cap a ponent

\section{PARADA 6 - CONDICIONAL. LES CINGLES DE RUPIT, (terme municipal de Rupit, comarca d'Osona). (Full 294).}

Després de realitzar la parada anterior, cal retornar cap a la carretera $C-153$, per tal de continuar cap a ponent. Així, en arribar al Coll de Cendreu, ens caldrà continuar cap a la població de Rupit. En arribar-hi, ens caldrà buscar un lloc proper a les Cingles de Rupit, per tal de fer una nova aturada, dintre del recorregut del present itinerari. Així, haurem recorregut uns 13 Km més.

En aquest recorregut, haurem trobat afloraments dels materials esmentats a les aturades anteriors. Aquets materials, de tonalitats eminentment grises, pel seu origen marí, són les apareixen a l'indret de la present aturada.

Al llarg d'aquest recorregut, haurem anat observant els relleus del Puigsacalm $i$ també el de Collsacabra a la dreta de la carretera que anem seguint. També, haurem vist com la Riera de Rupit va seguint una alineació molt clara, amb un relleu suau cap a llevant (les vessants occidentals dels dos cims acabats d'esmentar) $i$ un relleu més abrupte cap a ponent. En realitat, aquest curs d'aigua va seguint la falla de Rupit, que enlaira els materials cap a ponent (desplaçant-los alhora cap al NNW). esfondrant-los cap a llevant (cap el SSE).

En aquest lloc, aquests materials carbonatats que constitueixen les anomenades calcàries del Far, formen part d'una interesant cinglera. Els materials que la formen es 
superposen sobre els terrenys triàsics i paleozoics de la Serralada Prelitoral Catalana. Aquests materials es troben al fons de la vall, als embassaments de Sau i Susqueda, visibles des de l'indret de l'aturada.

Entre els materials cenozoics de Depressió Geològica de 1’Ebre (on ara som), es fan palesos uns nivells calcolutites $i$ sorrencs, de tonalitats grisenques. Aquests materials pertanyen a la Formació Puigsacalm. Per sota d'aquests, es fan palesos uns afloraments rogencs (de caràcter eminentment detrític, sorrenc), que pertanyen a la Formació Vilanova de Sau.

PARADA 7. LES CINGLES DE L'AVENC DE TAVERTET, (terme municipal de Tavertet, comarca d'Osona). (Full 294).

Després de realitzar la parada anterior, cal retornar cap a la carretera C-153, per tal de continuar el recorregut cap a ponent. Més endavant, en arribar al trencall de la pista que dirigeix cap a Taradell, ens caldrà agafar-la (aquesta es troba a uns 3'5 Km de Rupit). Després d’agafar aquesta pista, haurem de recórrer uns $4 \mathrm{Km}$ més, per tal d'arribar a les immediacions de l'Avenc de Tavertet. Així, haurem recorregut uns $8 \mathrm{Km}$ més, de de població de Rupit.

En aquest recorregut, haurem trobat afloraments dels materials cenozoics esmentats a l'aturada anterior. Alhora, haurem travessat la falla de Rupit, trobant-nos ara al bloc enlairat de ponent. Entre afloraments dels materials carbonatats de les calcàries del Far, que aquí formen un interessant cingle. Per d'altra banda, sobre aquestes calcàries s $\mathrm{s}$ ha desenvolupat un interessant poljé. FOTOGRAFIA 10.

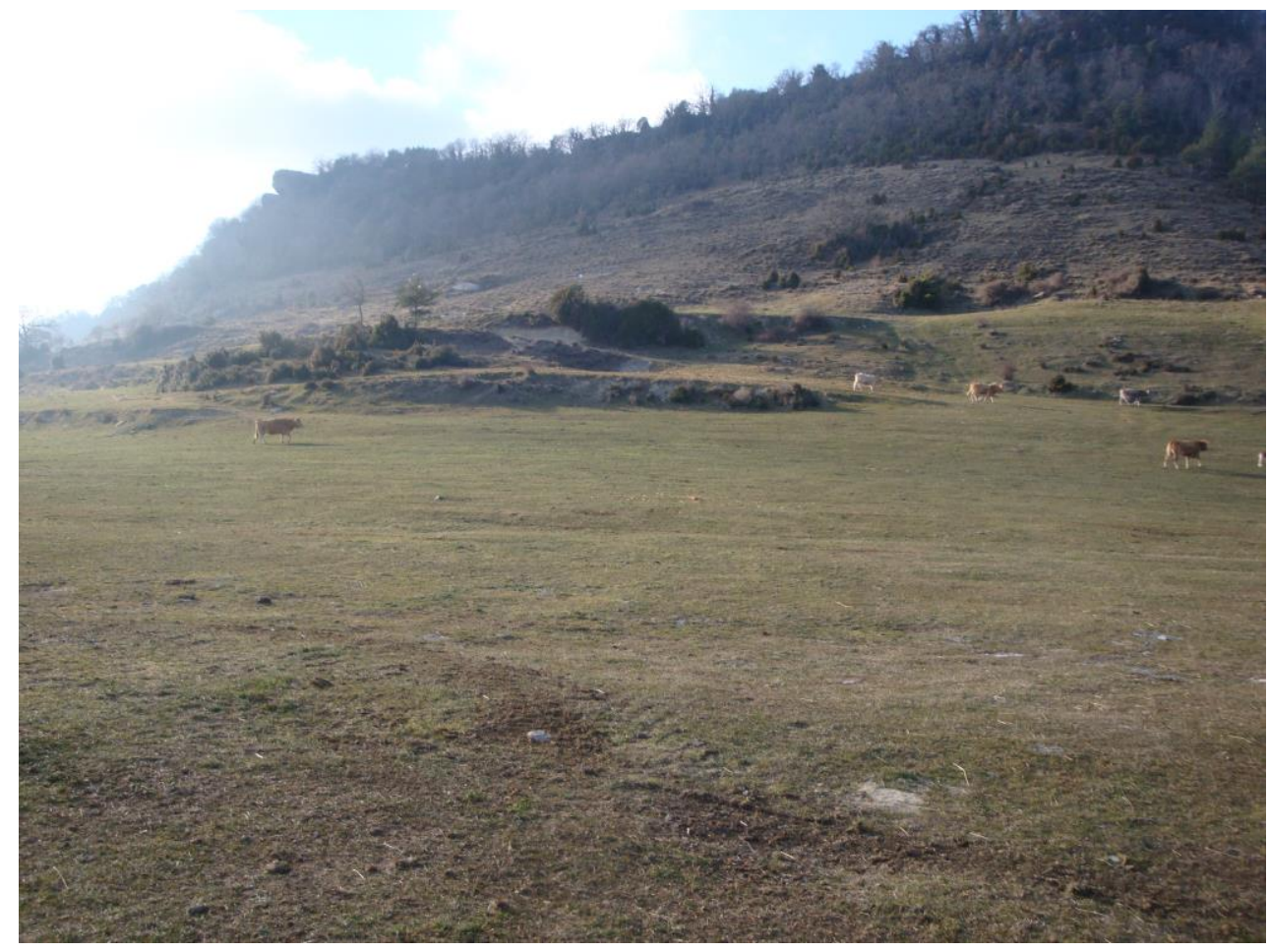

FOTOGRAFIA 10

Poljé de l'Avenc de Tavertet 
Per d'altra banda, prop de l'indret anterior, es troben els interessants Cingles de l'Avenc de Tavertet. Des d'aquest indret, mirant cap a llevant es poden veure els Cingles del Far i també com les calcàries que hi apareixen (les calcàries del Far) es van esfondrant cap a Rupit, enlairant-se on ara som, a l'altre cantó de la falla de Rupit. També es pot veure com per sota de les calcàries afloren els materials rogencs (amb gresos i calcolutites) de la Formació Vilanova de Sau. FOTOGRAFIA 11.

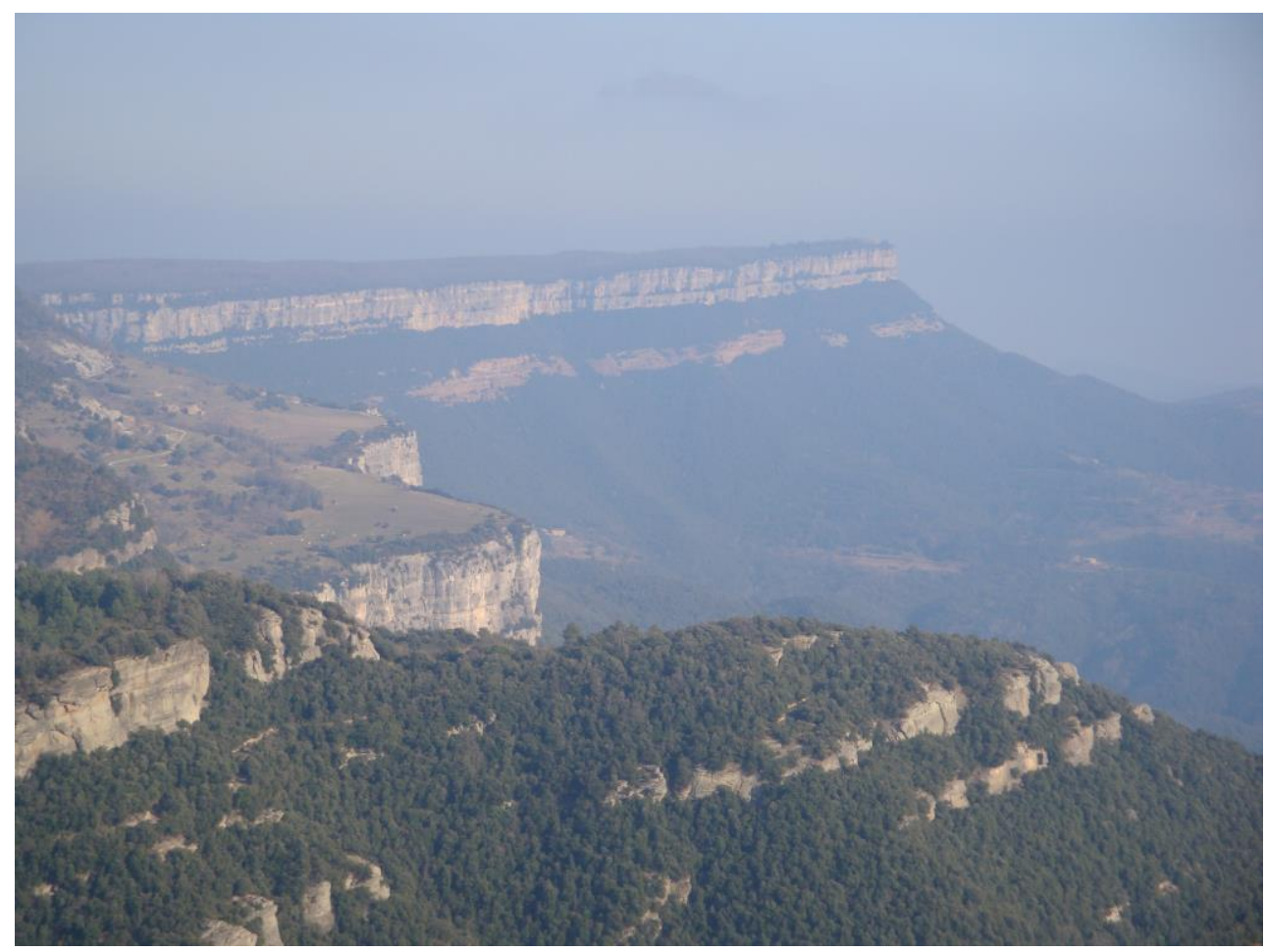

FOTOGRAFIA 11

Cingleres del Mirador del Far i de Rupit, des de les Cingles de l'Avenc de Tavertet Es pot veure com les anteriors s'esfondren en relació a les darreres, d'es d'on es pren la fotografia. També es pot veure que per sota de les calcàries del Far, hi ha els gresos rogencs de Vilanova de Sau

PARADA 8. LES CINGLES DE TAVERTET, (terme municipal de Tavertet, comarca d'Osona). (Full 333).

Després de realitzar la parada anterior, cal de nou continuar el recorregut cap a ponent pel camí que es dirigeix cap a la propera població Tavertet. En arribar-hi, podem fer una nova aturada, a uns $5 \mathrm{Km}$ de l'anterior.

Com als recorreguts anteriors, en aquest tram, hem continuat trobant afloraments dels materials que reblen la Depressió Geològica de l'Ebre, on estem ara situats. Aquests materials (per aquests indrets) són eminentment marins. Així haurem trobat els afloraments de les denominades calcàries de Tavertet (que equivalen a les calcàries del Far) En ambdós casos es tracta de calcaries de l'Eocè molt fossilíferes, fonamentalment de nummulites Aquests nivells carbonatats formen un espectacular cingle, sobre el que s'assenta la població de Tavertet. Des d'aquest indret es pot observar la cinglera, que 
s’enlaira sobre la vall del riu Ter. FOTOGRAFIA 13 i 14.

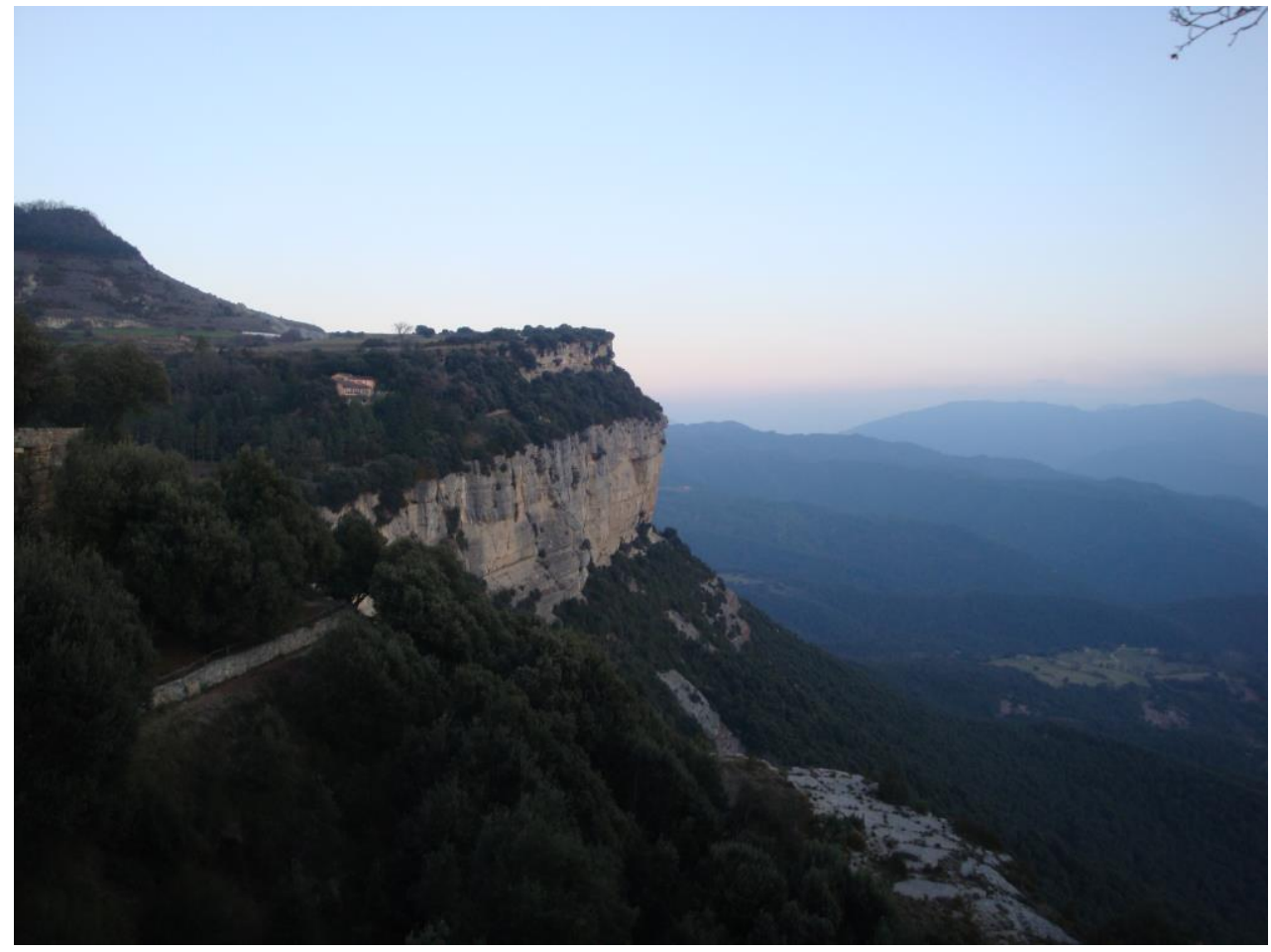

FOTOGRAFIA 12

Us aspecte de les conegudes Cingles de Tavertet

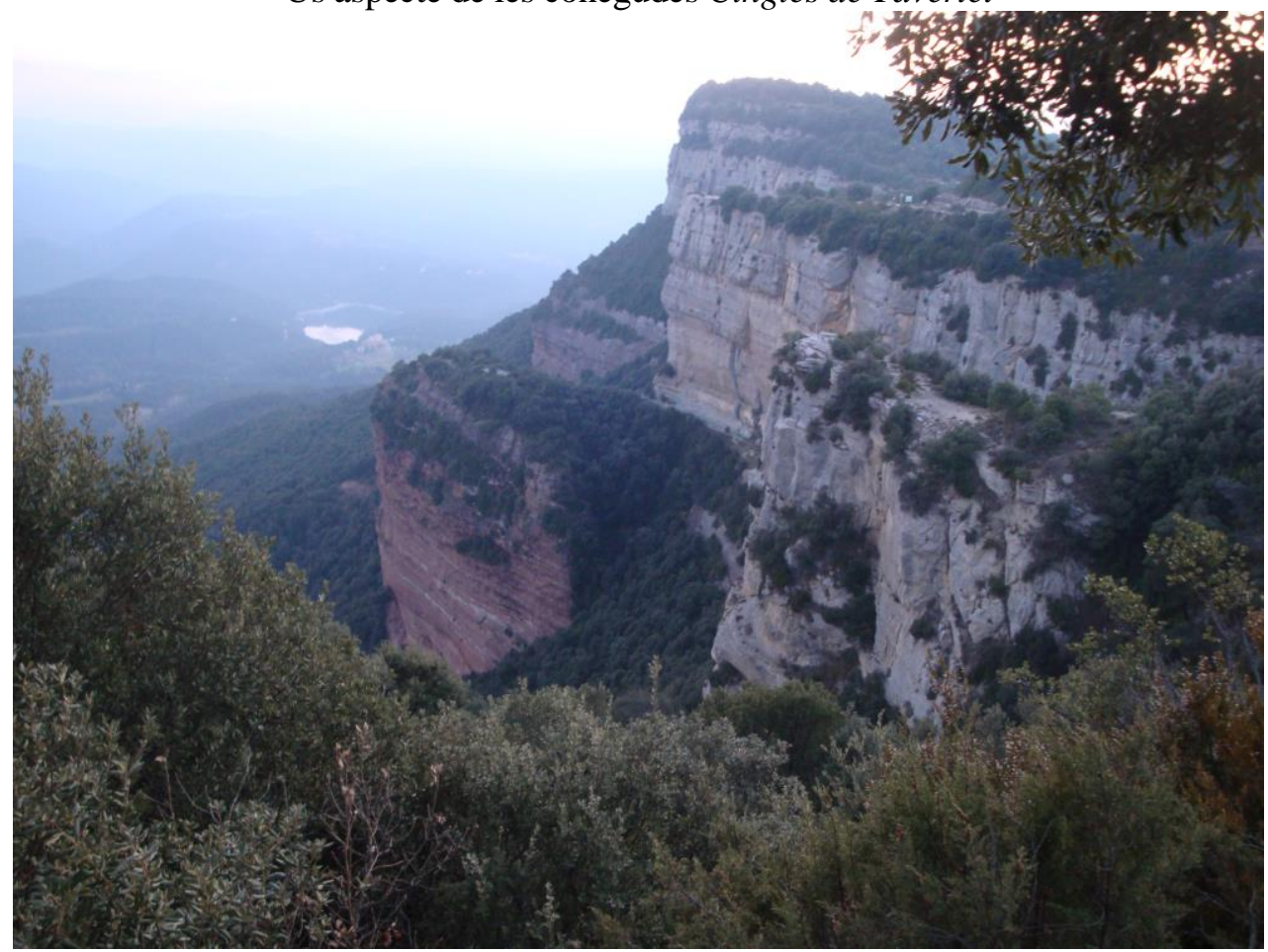

FOTOGRAFIA 14.

L'aflorament d'aquestes calcàries, posa de manifest un conjunt de falles que les enlaire cap a ponent. Per sota de les calcàries apareixen els materials de la Formació Vilanova de Sau

Després de realitzar l'aturada anterior, cal la possibilitat de continuar cap a 1'Esquirol (Santa Maria del Corcó), per tal de seguir cap a Vic per la carretera C-153, 
on podria acabar aquest itinerari.

EN AQUEST LLOC FINALITZA EL PRESENT ITINERARI.

\section{BIBLIOGRAFIA}

ARAÑA, S. et altri (1983).- El volcanismo neógeno-cuaternario de Catalunya: caracteres estructurales, petrográficos y geodinámicos. Acta Geológica Hispánica, 18 (1), pp. 1-17, Barcelona.

DURAN, H. i GOLD, E. (1990).- Itinerario por el Paleozoico de les Guilleries. Inédito. Barcelona

GASSIOT, X. i RIERA, M. (1981).- Itinerari per la Zona Volcànica de Catalunya. Pub. ICE$U A B, 36$ pàgines. Barcelona.

GUIMERÀ, J. et altri (1992).- Geologia (II), Història Natural dels Països Catalans, Vol. 2, 547 pag. Enciclopèdia catalana, S.A., Barcelona.

IGME (1994a).- Mapa Geológico de España a escala 1:50.000, Segunda série, Primera edición. Hoja y memória $\mathrm{n}^{\mathrm{o}} 256$ (Ripoll). Ins. Geominero y Tecnológico de España. Ministerio de Indústria y Energia. Madrid.

IGME (1994b).- Mapa Geológico de España a escala 1:50.000, Segunda série, Primera edición. Hoja y memória n 257 (Olot). Ins. Geominero y Tecnológico de España. Ministerio de Indústria y Energia. Madrid.

MALLARACH, J. M. (1968).- Carta Geològica de la Regió Volcànica d’Olot. Edit.. Ajuntament d'Olot. Olot.

MALLARACH, J.M. i RIERA, M, (1981).- Els volcans olotins i el seu paisatge. Edit. Serpa. Barcelona.

MATA-PERELLÓ, J.M. (1991).- Els Minerals de Catalunya. Arxius de la Secció de Ciències, t. XCIII. Institut d'Estudis Catalans. Barcelona.

MATA-PERELLÓ, J.M. (1996).- Apunts per a un itinerari geològico - mineralògic per les comarques del Ripollès i de la Garrotxa: des de Campdevànol a Santa Pau, i a Sant Joan de les Fonts. Inèdit. 10 pàgines. Manresa

MATA-PERELLÓ, J.M. (1999).- Itinerari geològic - mineralògic per les comarques de la Garrotxa i de la Selva: des de les Preses a Sant Julià del Llor. Inèdit. 10 pàgines. Manresa

MATA-PERELLÓ, J.M. (2007).- Recorregut geològic i miner per les comarques de la Garrotxa i del Ripollès: des del Coll de Bracons a les Preses, Olot i a Sant Joan de les Abadesses. Inèdit. 10 pàgines. Manresa

MATA-PERELLÓ, J.M. (2012).- Itinerari geològico - mineralògico per les comarques de la Garrotxa i d’Osona: des de les Preses al Far, Rupit, Cantonigrós i a Vic. Inèdit. 8npàgines. Manresa

RIBA ARDERIU, O. Et altri. (1976).- Geografia Física dels Països Catalans. Edit Ketres. 


\section{Barcelona.}

